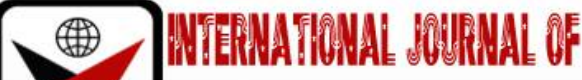

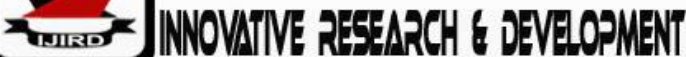

ISSN 2278-0211 (Online)

\section{Effect of Rational Emotive Behaviour Therapy (REBT) on Change of Aggressive, Violent and Anger Behaviours of Technical Students}

\author{
Osaigbovo Louis Odaro \\ Senior Lecturer, Department of Vocational and Technical Education, \\ University of Benin, Benin City, Edo State, Nigeria \\ Abusomwan Sunday Bello \\ Senior Lecturer, Department of Vocational and Technical Education, \\ University of Benin, Benin City, Edo State, Nigeria
}

\begin{abstract}
:
The paper examined the effect of rational emotive behavior therapy on the item change of aggressive, violent and anger behaviours of Senior Secondary Technical students of Edo and Delta States. The instrument used to collect data for the study was the Technical Student Violent Behaviour questionnaire (TSUB) which was a 15 items instrument and tested for reliability which yielded reliability of 0.72 using Cronbach alpha. The design of the study is a Quasiexperimental Design and Behavior the t-test independent variables was used to test the hypotheses while mean and standard deviation was used to answer the research questions. The findings of the study indicate that rational emotive behaviour therapy (REBT) is very effective in the treatment of aggressive, violent and anger behaviours of Senior Secondary Technical College Students in Edo and Delta states of Nigeria. The recommendations amongst others includes that teachers should be trained on the effective use of REBT on the treatment of aggressive, violent and anger behaviours of Senior Secondary Technical College students.
\end{abstract}

Keywords: Rational emotive behaviour therapy, anger, violent, aggression, technical students

\section{Introduction}

Over the years, aggression, anger, violence, rage and intimidation have characterized the attitudes of adolescents and young adults including teens and children. These attitudes have affected performances in schools and had hindered academic gains in the young victims. These negative attitudes had become a way of life to so many people. The construct of their negative attitudes could be explained as the experiences of a marked physiological distress when faced with evaluative situations or events which the individual react to. Anger and rage are irrational attitudes common with adolescents which produce feelings of hate ranging in intensity from mild annoyance to uncontrollable rage. These are character and behavioral changes that educationists and researchers had been striving to effect.

Ellis according to Wayne (2005), stated that you feel the way you think. He further stressed that problematic emotional reaction are caused by negative self-talk, which are accounts for catastrophic thinking. Catastrophic thinking involves unrealistic negative appraisals of stress that exaggerates the magnitude of unpleasant experiences. Ellis therefore propounded basic principle of A-B-C sequence to explain this idea of rational emotive behavior therapy (REBT). In the therapy sequence, A is referred to as activity, an unpleasant event that produce stress, such as minor workshop accident, misunderstanding, delay while queuing up for lunch, or failure to get a good grade when he is expecting it. B stands for belief system about the event or the personal appraisal of the stress. According to Ellis, people often view minor setbacks as disasters. Thus they engage in catastrophic thinking. "how awful this is, I cannot stand it."I must retaliate at higher dimension. Once beaten, twice shy, one bad turn deserves another. On the other hand, $\mathrm{C}$ stands for consequences of your negative thinking. When your appraisal of stressful events is overtly negative, the consequences tend to be emotional distress. Thus people feel angry, anxious, outraged, panic stricken disgusted, depressed, exasperated, deranged and violent.

Most people do not understand the importance of phase B in this three-stage sequence of REBT. They mostly think that the activating event A causes the consequent emotional turmoil C. However, Ellis had pointed that A does not cause emotional distress C,it only appears to do so. Ones emotional distress is actually caused by ones catastrophic thinking in appraising stressful event. Hence the very first tenets of Rational Emotive Behavior Therapy Theory as propounded by Ellis is that virtually all humans, including bright and competent people, showed evidence of major human irrationalities and self-defeatism. 
These explain the causative factors of violence, aggression and anger behaviors among people of all cultures and races. The essence of these behavioural attitudes in all persons cannot be over emphasized as the society has become prone to violent behaviours resulting into insurgencies, religious intolerance and attack, cultism and assassinations. This view is supported by Abdullahi (2012) who asserted that violence has brought miseries, anguish and pains to many parents, teachers, school authorities and the government which had led to loss of students' lives, school dropout, and disruption of peace in the society.

Students' involvement in aggression and violence is so alarming and has resulted to loss of control as they become addicted to hard drugs such as Marijuana, Tramadol and Dry Gin. With the use of these drugs they become hardened to their feelings and conscience. They fight their offender at any slight opportunity with or without provocation. Violence is an expression of anger which may take the form of self-harm and more commonly physical or verbal assault and abuse. Anger problems may have early manifests in the Junior School and Senior School years (Charleswoth, 2018). During the developmental period adolescents often search for autonomy, identity and independence. In the quest of growing some adolescents struggle with strong emotions like anger and aggression. Broderick and Jennings (2012) stated that the pivotal years of adolescents are coupled with anger and aggression which can create a perfect violent storm in the context of degenerated emotional development.

\subsection{Statement of the Problem}

Violence in adolescent school age has become a source of worry to most parents. Parents are apprehensive of taking their children to public schools because they are afraid that their wards would take-up negative and irrational behaviours that would make them to become violent in life.

The fear that the adolescents take up irrational attitudes in school had become a source of nightmare to school authorities and governments. Government has become worried that ways of eliminating violent behaviours from the populace is by preaching peaceful coexistence and responsible citizenship education and re-introduction of civic education to the curriculum of secondary schools. The use of guidance counselors in schools is to check the negative and irrational behaviours of adolescent school students so as to mitigate their violent tendencies.

In spite of all these, violence seems unabated. It is in light of the above that the researcher becomes worried to investigate the use rational emotive behaviour therapy (REBT) to control violence and aggression among secondary technical school students.

\subsection{Research Questions}

These research questions were raised to guide the study.

- What is the mean difference in the aggressive behavior of senior secondary technical schools students exposed to REBT and these not exposed to REBT.

- What is the meant difference between the violent behavior of senior secondary technical schools students exposed to REBT and those and exposed to REBT.

- What is the mean difference between the anger behavior of senior secondary technical schools students exposed to REBT and those and exposed to REBT.

\subsection{Hypotheses}

The above research questions were also hypothesized accordingly

There is no significant difference in the aggressive behaviours of senior secondary technical students exposed to REBT and those not exposed to it

There is no significant difference in the violent behavior of senior secondary technical schools exposed to REBT and those not exposed to it.

There is no significant difference in the anger behavior of senior secondary technical school students exposed to REBT and those not exposed to it

\subsection{Research Design}

The research design used for the study is the quasi-experimental design. It is the pretest, post test control group design. It takes the matrix form of

$\mathrm{O}_{1} \quad \mathrm{X}_{1}, \mathrm{O}_{2}$

Control group

$01, \quad \mathrm{X}, \quad \mathrm{O}_{3}$ Experimental group

$\mathrm{O}_{1}$, represents the date collected from the pre-tests score

$\mathrm{X}_{1}$, and $\mathrm{X}_{2}$ represents the treatments for control groups and experimental group respectively $\mathrm{O}_{2}$ and $\mathrm{O}_{3}$ represents the post test scores for control group and treatment group respectively.

\section{Methodology}

The population consists of 1,500 students of technical trades in technical colleges in Edo and Delta states

\subsection{Population and Sampling}

The sample for the study consists of the NTC II students of technical colleges in Benin City and Sapele respectively. The NTC students of Benin City Technical College is the experimental group while the NTC II students of Sapele Technical College is used as the control group. These are two intact classes that are not randomized. The experimental group is 87 students while the control group is 65 students totaling 152 students which make up the sample for the study. 


\begin{tabular}{|c|c|c|c|}
\hline Groups & Male & Female & Total \\
\hline Experimental & 52 & 35 & 87 \\
\hline Control & 42 & 23 & 65 \\
\hline
\end{tabular}

Table 1

\subsection{Research Instrument}

The research instrument is the Technical Students Violent Behavior Questionnaire(TSVB) designed by the author. It consists of 15 test items with 4point rating scale of strongly agreed, to stronglydisagree. Any item with a score of 2.5 and above is taken as agreed and below 2.5 is disagree. The REBT treatment comprise of disputation package of six weeks.

\subsection{Validation of Instruments}

The instrument was validated by two experts in the Department of Guidance and Counseling of the University of Benin, Benin City and Vocational and Technical Education Department of the University of Benin

The instrument was tested for reliability by Cronbach alpha method and this gives an $\mathrm{r}$ value of 0.72 respectively indicating that the instruments were reliable.

\subsection{Method of Data Collection}

The data was collected by the researchers by obtaining permission from the Boards of Teaching of Education from Edo and Delta state and the principal of each of the school to be used for the study. The instruments (TSVB) were administered to the intact classes of students for the experimental and control groups to obtain the pre-tests data.

The REBT treatment and lesson notes were thereafter administered to the experimental group for a period of 6 weeks while the control group was administered with only the lesson note for the period of six weeks before the post test scores were obtained from both the experimental and control groups by a second administration of the instrument TSVB.

\section{Method of Date Analysis}

The data collected was analyzed using mean and t-test of independent samples. Mean was used to answer the research questions while t-test of independent samples was used to analyse the hypotheses at 0.05 level of significance. Any mean above 2.5 would be regarded as, confirming the irrational behavior of aggression, violent behaviour and anger while any mean below 2.5 would be regarded as confirming a rational behavior of lack of aggression, lack of violent behavior and lack of anger.

\section{Analysis of Results}

\subsection{Research Question 1}

What is the mean difference inthe aggressive behavior of senior secondary technical students exposed to REBT and those not exposed to REBT

\begin{tabular}{|c|c|c|c|cc|}
\hline & No & $\begin{array}{c}\text { Smean1 } \\
\text { Pre-test }\end{array}$ & $\begin{array}{c}\text { Av Mean } \\
\text { Pre-test }\end{array}$ & $\begin{array}{c}\text { Mean 2 } \\
\text { Post-test }\end{array}$ & $\begin{array}{c}\text { Av Mean } \\
\text { Post-test }\end{array}$ \\
\hline $\begin{array}{c}\text { Experimental } \\
\text { group }\end{array}$ & 87 & 313.5 & 3.6 & 182.7 & 2.1 \\
\hline Control group & 65 & 244.5 & 3.6 & 224.0 & 3.5 \\
\hline
\end{tabular}

Table 2 Difference of Mean Score of Experimental and Control Groups

From the result presented in table above, the experimental and control group had a total mean of 321.9 and total mean of 244.5 respectively in the pre-test score of aggressive behavior of Senior Secondary Technical Schools Students. The small difference in the mean of both groups may be due to environmental influence. However the post-test mean score of 182.7 and2.1 average mean for experimental group. The control group had a gross mean of 224.0 and an average mean of 3.5. The negligible difference of 3.6 pre-test and 3.5 post-test could be regarded as the influence of the maturation period of the 6 weeks teaching on the control groups. Therefore the experimental group was significantly affected by the use of Rational Emotive Behaviour Therapy (REBT).

\subsubsection{Hypothesis One}

There is no significant difference in the mean aggressive behavior of SSTS students exposed to REBT and those not exposed to REBT.

\begin{tabular}{|c|c|c|c|c|}
\hline & No Mean & SD & Cal T. & Tab Crit \\
\hline Experimental Group & 87 & 42.5 & 4.5 & 8.2 \\
\hline Control group & 65 & 56.5 & 2.7 & 7.6 \\
\hline
\end{tabular}

Table 3: Table of T-Test of Independent Samples of Experimental and Control Groups

Form the analysis of the table 2 above, it was discovered that the calculated T score was 8.2 the critical table value was7.6. This implies that the null hypothesis of significant difference is rejected. This also implies that REBT has a significant effect on change of aggressive behavior. 


\subsection{Research Question 2}

What is the mean difference between violent behavior of Senior secondary Technical Schools Students exposed to REBT and those not exposed to REBT?

\begin{tabular}{|c|c|c|c|cc|}
\hline & No & $\begin{array}{c}\text { Emean1 } \\
\text { Pre-test }\end{array}$ & $\begin{array}{c}\text { Av Mean } \\
\text { Pre-test }\end{array}$ & $\begin{array}{c}\text { MMean 2 } \\
\text { Post-test }\end{array}$ & $\begin{array}{c}\text { Av Mean } \\
\text { Post-test }\end{array}$ \\
\hline $\begin{array}{c}\text { Experimental } \\
\text { group }\end{array}$ & 87 & 313.5 & 3.60 & 182.7 & 2.1 \\
\hline Control group & 65 & 237.3 & 3.65 & 235.1 & 3.61 \\
\hline
\end{tabular}

Table 4: Table of Grand Mean Score and Average Mean Score of Experimental and Control Groups on Violent Behavior

Table 4 above shows that the pre-test grand mean score 313.5 and 237.3 grand mean recorded for the experimental and control groups respectively which gave an average of 3.60. After the administration of REBT on the experimental group, it gave a grand mean of 182.7 which accounts for an average mean of 2.1 for the experimental group. The grand mean of 235.2 which gave an average mean 3.61for pre-test, the post test of the control group 235.0 which gave an average mean of 3.60 indicates a very minute change of behavior as a result of maturation of time of 6 weeks for the control group which is not significant

\subsubsection{Hypothesis Two}

There is no significant difference between the mean violent behavior of Senior Secondary Technical School Students exposed to REBT and those not exposed to REBT.

\begin{tabular}{|c|c|c|c|c|}
\hline Group & No & SD & Cal. T & Tab Crit \\
\hline Experimental group & 87 & 41.5 & 4.2 & 8.2 \\
\hline Control group & 65 & 57.5 & 2.6 & 7.6 \\
\hline
\end{tabular}

Table 5: Table of the T-Test of Independent Samples of Violent Behavior of Senior Secondary Technical School Students Exposed to REBT and Those Not Exposed to REBT

From the above analysis the mean score of violent behavior of the Senior Technical School Students was 41.5 and that of the control group was 57.5 with a Standard Deviation of 4.2 and 2.6 respectively. The calculated T score was 8.2 whereas the table critical was 7.6 indicating that there was a significant difference between the violent behavior of the two groups.

\subsection{Research Question 3}

What is mean difference between the anger behavior of Senior Secondary Technical School Students exposed to REBT and those not exposed to REBT?

\begin{tabular}{|c|c|c|c|cc|}
\hline Group & No & $\begin{array}{c}\text { Emean1 } \\
\text { Pre-test }\end{array}$ & $\begin{array}{c}\text { Av Mean } \\
\text { Pre-test }\end{array}$ & $\begin{array}{c}\text { EMean 2 } \\
\text { Post-test }\end{array}$ & $\begin{array}{c}\text { Av Mean } \\
\text { Post-test }\end{array}$ \\
\hline Experimental group & 87 & 330.5 & 3.8 & 186.2 & 2.1 \\
\hline Control group & 65 & 240.5 & 3.7 & 239.6 & 3.7 \\
\hline
\end{tabular}

Table 6: Table of Mean Score of Anger of the Experimental and Control Groups of Students

Table 6 above shows the mean score of anger of Senior Secondary Technical Schools students. The grand mean of 330.5 which accounts for 3.8 mean for the pretest for the experimental group while the grand mean of 240.5 which amount to 3.7 average mean of the control group. After the treatment, the post-test grand mean of 186.2 which gave an average mean of 2.1 as compared to grand mean of 239.6 and average mean of 3.7 for the control group. This shows that the REBT treatment was effective in the treatment of anger behaviour of Senior Secondary Technical Schools Students.

\subsubsection{Hypothesis Three}

There is no significant difference between the anger behavior of SSTS students exposed to REBT and those not exposed to REBT.

\begin{tabular}{|c|c|c|c|c|}
\hline Group & No & Mean Diff & Cal. T & Tab Crit \\
\hline Experimental group & 87 & 42.5 & 4.0 & 8.5 \\
\hline Control group & 65 & 56.5 & 2.5 & 7.3 \\
\hline
\end{tabular}

Table 7 above show that the calculated T score is 8.5 while the table critical gave a reading of 7.3 hypothesis three is therefore rejected. This indicates that there is a significant difference between the anger behavior of SSTS students exposed to REBT and those not exposed to REBT. 


\section{Discussion of Findings}

The result of the study shows that schools REBT (Rational Emotive Behaviour Therapy) is very useful in ameliorating irrational behavior of Senior Secondary Technical School Students in Edo and Delta states of Nigeria.

This result is in consonance with that of Hyland, McCindy, karatias, Murply, Vallieries and Power (2018) who studied the relationship between rational emotive behavior therapy on the irrational feeling of the experience of loneliness and anger. The result is also supported by studies carried out by Mangayakarasi and Sellakumar (2017) who designed a study to explore the efficacy of rational emotive behavior therapy on management of depression of HIV infected women of middle age and adolescents. It should be noted that rational emotive behavior therapy included in every day lesson plans in which students are lightly admonished to dissuade them from irrational thoughts while also condemning violent behaviours in all ramifications.

\section{Summary and Conclusion}

The uses of violent behaviours that have characterized schools in recent times leave much to be desired. Students learn violent behaviours in school and manifested them in cults and hooliganism. The Senior Secondary Technical Schools are like a training ground for violent behaviors among the adolescent students. Incidents of violent behaviours in schools and colleges abound and are growing on daily basis.

This research aimed at incorporating rational emotive behavior therapy in Senior Secondary Technical Schools is therefore apt so as to ameliorate the increasing incidences of violent behaviours amongst the students. Youths and adolescents are the adults of tomorrow and if their irrational thoughts and reasoning could not be corrected at the early stage, then a society of riotous and violent individuals would emerge in the future and people would not be pricked when causing harm and hurt to their fellow men. The elemental factors which are considered as variables for violent behaviors are aggression or aggressive behavior, violent behavior and anger behavior.

These three variables were tested using the instrument Technical Students Violent Behaviour (TSVB) in a quasiexperimental pretest and posttest design experiment. The population of the subjects was 152 made up of 7 intact classes of experimental and control groups. The REBT treatment was administered to the experimental group alongside their usual class lessons while the control group were given their class lessons. The pretest and post test scores were obtained which were also analysed using the mean and t-score of independent variables.

The results obtained shows that there is a significant difference in the behavior of students exposed to REBTin the experimental group as compared to the control group. The result further indicates that REBT is very effective in the treatment of students' anger behavior, treatment of students' aggressive behavior, and treatment of students' violent behaviours.

\section{Recommendation}

The following recommendations were made based on the findings of the study.

- Teachers should be trained on effectively using the rational emotive behavior therapy in counseling students during teaching in classes

- Students should be made to go through rational emotive behavior therapy classes as part of a weeklong orientation programme on admission to upper classes of secondary technical schools and colleges.

- Rations emotive behavior therapy should be incorporated into or combined with each lesson during lesson delivery in classes to guide students from irrational reasoning.

\section{References}

i. American Psychological Association (1996). Violence and socio-economic status.APA journal.org Retrieved 2011

ii. Bunwareen, T. (1999).Violence in schools in Mauratius. Educational journal in Africa.31

iii. Ellis, A. \& Bernard, M.E. (2005). Rational emotive behavioural approaches to childhood disorders. Theory, practice and research. New York: Springer Publishing.

iv. Ellis, A. \& Bernard, M.E. (2006). Rational emotive behavioural approaches to childhood disorders (theory, practice and research), United States of America. Springer Science + Business Media Inc.

v. Charlesworth, J. R. (2018). Helping adolescents manage anger. Alexandria, VA: American Counseling Association.

vi. Broderick, P. C., \& Jennings, P. A. (2012). Mindfulness for adolescents: A promising approach to supporting emotion regulation and preventing risky behavior. New Directions for Student Leadership, 136, 111-126

vii. Hyland, P.; McGinty, G.; Karatzas, T.; Murph, J.; Vallieres, F. \& Power, M. (2018). Can the REBT theory explain loneliness? Theoretical and clinics application. http://dotline.org/10. 1080/165060730.2018.1475505.

viii. Moore, S.L. (2018). Annihilation Anxiety and Parental Representation in Adolescents, Unpublished thesis, Department of Psychology, Pace University, New York.

ix. Nasir, R. \& Ghani, N.A. (2014).Behavioural and emotional effects of anger expression and management among adolescents. Science direct. Available online@www.science.direct.com.

x. Ntamu, B.A. (2017). Effects of rational emotive behaviour therapy (REBT) on curbing examination malpractice behaviour among public secondary school students in Calabar municipality. International Journal of Scientific Research in Education, 10(4)., 440-450. Retrieved 10

xi. Obikeze, N.J. \& Obi, I.(2015). Prevalences and incidences of aggressive behaviours among adolescents in Senior Secondary Schools in Anambra State. Igbariam Educational Research Amambra State University 
xii. Posternak, M., \& Zimmerman, M. (2012).Anger and aggression in psychiatric outpatients.Journal of Clinical Psychiatry, 63, 665-672.

xiii. Redford, P. (2014). Self-construal and anger action tendencies in Hong Kong and the United Kingdom.Merging past, present, and future in cross-cultural psychology, 367-386.

xiv. Saba, A. (2015). Effectiveness of rational emotive behavior therapy in disputing irrational beliefs of persons with substance used disorders. Presentation, 4th International Conference and Exhibition on Addiction Research\& Therapy.August 03-05, 2015 Florida, USA.

xv. Samuolis, J., Barcellos, M., LaFlam, J., Belson, D., \& Berard, J. (2015). Mental health issues and their relation to identity distress in college students. Identity: An International Journal of Theory and Research, 15, 66-73. doi:10.1080/15283488.2014.989443

xvi. Shumba, S (2001). A case of incidence of abuse in schools in Zimbabwe. Educational journal of African 21(2) Retrieved July 2018.

xvii. Slaby, R., \& Guerra, N. (2018).Cognitive mediators of aggression in adolescent offenders. Developmental Psychology, 24 (4), 580-588.

xviii. Smith, S., Stephens, H., Repper, K., \& Kistner, J. (2016).The relationship between anger rumination and aggression in typically developing children and high-risk adolescents. Journal of Psychopathology and Behavioral Assessment, 38, 515-527. doi: 10.1007/s10862-016-9542-1.

xix. Stephenson, E.; Watson, P.J.; Chen, Z.J. \& Morris, R.J. (2017).Self-compassion, self-esteem and irrational beliefs. Cur Psychol Dol. 10.1007/512144-17-9563-2.

xx. Sukhodolsky, D., Smith, S., McCauley, S., Ibrahim, K., \& Piasecka, J. (2016). Behavioral interventions for anger, irritability, and aggression in children and adolescents. Journal of child and adolescent psychopharmacology, 26, 58-64. doi:10.1089/cap.2015.0120

xxi. Suls, J., \& Bunde, J. (2015). Anger, anxiety, and depression as risk factors for cardiovascular disease: The problem and implications of overlapping affective dispositions. Psychological Bulletin, 131, 260-300.

xxii. Yulia, R.A. \& Edi, P. (2018).The effectiveness of rational emotive behaviour group counseling against the assertive behaviour of students SMP NIML at, Sleman, Yogyakarta. Advances in Social Science, Education and Humanities Research, Vol. 323. 